\title{
Experimental study of graphene oxide suspension in drilling Ti-6Al-4V
}

\author{
Shuang $\mathrm{Yi}^{1, \mathrm{a}^{*}}$, Guangxian $\mathrm{Li}^{1, \mathrm{~b}}$, Songlin Ding ${ }^{1, \mathrm{c}}$ John Mo ${ }^{1, \mathrm{~d}}$ and M. Rahman ${ }^{2, \mathrm{e}}$ \\ ${ }^{1}$ School of Engineering, RMIT University, Australia \\ ${ }^{2}$ Department of Mechanical Engineering, National University of Singapore, Singapore \\ aS3516088@student.rmit.edu.au, bS3463966@student.rmit.edu.au, \\ csonglin.ding@rmit.edu.au, dohn.mo@rmit.edu.au,mpemusta@nus.edu.sg
}

Keywords: Titanium alloy, WC, Drilling, Graphene oxide, Cutting fluids

\begin{abstract}
This paper investigates the wear mechanism of WC (tungsten carbide) drills in drilling titanium alloy (Ti-6Al-4V) with graphene oxide suspended cutting fluid and conventional coolant. By analysing cutting forces and examining the worn surface of the drills, wear progression in the cutting experiments were discussed. A significant reduction in cutting force and tool wear was found in cutting Ti-6Al-4V with graphene oxide suspended cutting fluid compared to conventional coolant. The causes led to such changes were presented.
\end{abstract}

\section{Introduction}

Titanium and its alloys have been widely used in automotive, aerospace and biomedical industry owing to their excellent properties including high tensile strength and toughness, light weightstrength ratio and extraordinary corrosion resistance. However, Titanium alloys are difficult to machine due to their low thermal conductivity and high chemical activities. A lot of research had been conducted to reduce cutting temperature in order to increase tool life and improve machining efficiency. For example, Minton et al. [1] investigated indirect cooling with a diamond-coated internally-cooled cutting tool whilst machining titanium. Yamaguchi et al. [2] found that magnetic abrasive finishing of cutting tools could reduce cutting heat in machining of titanium alloys, because of the reduction in friction at the chip-tool interface and thus extend tool life. Huang et al. [3] investigated the drilling of SiCp/Al metal matrix composite with PCD tools and found the higher the cutting speed, the better the surface finish. Recently, various attempts to reduce tool wear have been made by using different coolants such as liquid nitrogen, powder suspended oil and water. For example, Davim and Mata [4] found that cryogenic cooling had substantially reduced the grinding zone temperature. However, due to the limited improvements achieved, these technologies have not been widely applied in practice. Graphene is a thin layer of pure carbon; it is a single, tightly packed layer of carbon atoms that are bonded together in a hexagonal honeycomb lattice. It is the best-known two-dimensional material, with its atom-thick layers proving plenty of fascinating material properties. One of the outstanding properties is its excellent thermal conductivity: the thermal conductivity of suspended graphene oxide is as high as $5300 \mathrm{~W} \cdot \mathrm{m}^{-1} \cdot \mathrm{K}^{-1}[5]$, this makes for graphene oxide suspensions an excellent media which can be applied as cutting fluid [6]. Chu et al. [7] developed a canola-based cutting oil enhanced with graphene platelet (GPL) additives for high performance micro-machining applications, and found that graphene colloidal suspensions was an excellent alternative cutting fluid in reducing cutting temperature. In the past decades, graphene based cutting fluids had been tried in many applications for the machining of steel materials [8]. However, little research has been done to use graphene oxide powder suspended cutting fluid to drill titanium alloy, and it is unclear how the effects of graphene oxide suspensions are on cutting tools and workpiece.

This paper investigated the drilling of Ti-6Al-4V with $\mathrm{WC}$ tools and graphene oxide powder suspended coolant. Cutting forces and tool wear, which are important factors indicating the effectiveness of the new coolant, were analysed. In order to find the increase in cutting performance, two types of coolants were applied and results were compared. 


\section{Experimental set up}

\subsection{Workpiece and tool material}

Ti-6Al-4V has excellent mechanical properties (Table 1) such as high hardness, high strength-toweight ratio, low modulus of elasticity and superior corrosion resistance. A workpiece block with the dimension of $150 \mathrm{~mm} \times 100 \mathrm{~mm} \times 25 \mathrm{~mm}$ was used in the experiments. A commercial WC twist drill bit made by ISCAR (ISCARSCD 080-043-080) was applied. The diameter of the drill was 8 $\mathrm{mm}$ and the point angle was $140^{\circ}$.

Table 1 Workpiece material Ti-6Al-4V properties

\begin{tabular}{|c|c|c|c|c|c|}
\hline $\begin{array}{c}\text { Hardness } \\
(\mathrm{HV} 20)\end{array}$ & $\begin{array}{c}\text { Ultimate tensile } \\
\text { strength }(\mathrm{MPa})\end{array}$ & $\begin{array}{c}\text { Yield strength } \\
(\mathrm{MPa})\end{array}$ & $\begin{array}{c}\text { Elastic modulus } \\
(\mathrm{GPa})\end{array}$ & $\begin{array}{c}\text { Density } \\
(\mathrm{g} / \mathrm{cm} 3)\end{array}$ & $\begin{array}{c}\text { Thermal Conductivity at } \\
20 \circ \mathrm{C}(\mathrm{W} / \mathrm{mK})\end{array}$ \\
\hline 600 & 832 & 745 & 113 & 4.5 & 6 \\
\hline
\end{tabular}

\subsection{Cutting fluid and graphene oxide}

The baseline cutting fluid to be used was ROCOLUltracut Clear coolant. It is a biocide protected no rancidity coolant with a high dilution rate of 70:1. Its composition is shown in Table 2.

Table 2 Composition of the ROCOLUltracut Clear coolant

\begin{tabular}{|c|c|c|}
\hline Mineral oil (\%) & Saponified natural oil (\%) & Water (\%) \\
\hline 20 & 20 & 60 \\
\hline
\end{tabular}

The parameters of graphene oxide powder used in the experiments are shown in Table 3. The graphene oxide powder suspended fluids were made by mixing the few-layer graphene oxide powder in ROCOLUltracut Clear cutting fluid; the concentration proportion of the coolant was 1:40 (250ml RocolUltracut Clear cutting fluid and 10L water).

Table 3 Graphene oxide parameter

\begin{tabular}{|c|c|c|c|}
\hline Thickness(nm) & Layer diameters(um) & Layer & Specific surface area $(\mathrm{m} 2 / \mathrm{g})$ \\
\hline $1.0-1.77$ & $0.5-5$ & 5 & $300-450$ \\
\hline
\end{tabular}

\subsection{Drilling experiments}

The drilling experiment was carried out on a 3-axis CNC vertical milling machine (HASS VF1). A small pumping system was designed to apply the graphene coolant in the machining process. A six component dynamometer (Kistler 9257B) was used to measure the thrust force and torque. An eight channel charge amplifier (Kistler 5070A) was used to amplify the thrust force and torque signals which were transferred to the data acquisition card (NI DAQ DE6213). The signals were processed with LabView. The workpiece was mounted on the dynamometer, which connected with the data acquisition system. The bottom surface of the coolant tank was fixed between the workpiece and the dynamometer.

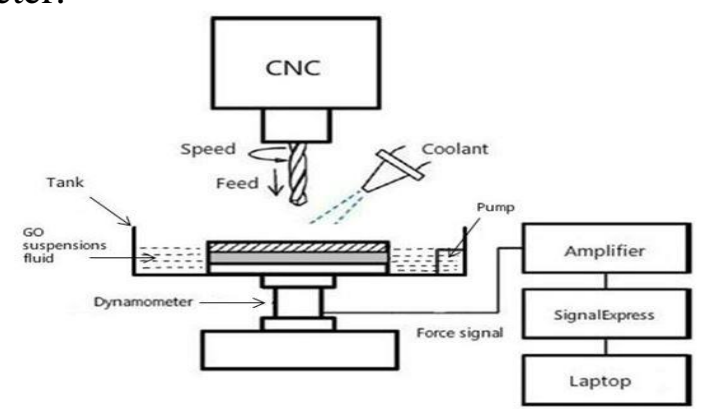

Fig.1. Schematics of drilling experimental set up

In order to compare the effects of graphene oxide suspensions fluid, four groups of experiments with two experiments in each group were designed. One was for the drilling with conventional coolant, the other was for the drilling with of graphene oxide suspensions fluid. The two experiments in each group were conducted with two tools of the same type. One was used for 
drillings with conventional coolant, the other one was dedicated to tests with graphene oxide suspensions fluid. Cutting parameters used in the drilling experiments are shown in Table 5 (a) and (b)

Table 5 (a) Machining parameters

\begin{tabular}{|c|c|c|c|c|}
\hline \multicolumn{5}{|c|}{ (a) Machining condition $(0.1 \mathrm{~mm} / \mathrm{rev})$} \\
\hline Cutting speed (rpm) & 800 & 1600 & 2400 & 2880 \\
\hline Baseline cutting fluid & 1 & 3 & 5 & 7 \\
\hline Baseline cutting fluid with GO & 2 & 4 & 6 & 8 \\
\hline
\end{tabular}

Table 5 (b) Machining parameters

\begin{tabular}{|c|c|c|c|c|}
\hline \multicolumn{6}{|c|}{ (b) Machining condition (1600 rpm) } \\
\hline Feed rate(mm/rev) & 0.1 & 0.12 & 0.15 & 0.18 \\
\hline Baseline cutting fluid & 9 & 3 & 11 & 13 \\
\hline Baseline cutting fluid with GO & 10 & 4 & 12 & 14 \\
\hline
\end{tabular}

\section{Results and discussion}

\subsection{Drilling forces}

The cutting forces in $\mathrm{Z}$ direction (thrust force) measured in the eight experiments were potted in Fig.2. The blue curve NC describes the forces when conventional coolant was applied while the curve in red color GC indicates when graphene oxide suspensions fluid was applied. It can be seen in Fig. 2 that when the spindle speed was $800 \mathrm{rmp}$, the cutting force with conventional coolant was $1421 \mathrm{~N}$ while it was $1287 \mathrm{~N}$ when graphene oxide suspensions fluid was applied. The percentage of force reduction in this case was $9.42 \%$. When spindle speed was increased to $2880 \mathrm{rpm}$, the cutting force was $1062 \mathrm{~N}$ with conventional coolant, and it dropped to $946 \mathrm{~N}$ when graphene oxide suspensions fluid was applied, the reduction rate was up to $10.92 \%$. This significant drop of cutting force was attributed to the large amount of cutting heat taken away by the graphene oxide suspensions fluid, which in turn reduced the cutting temperature at the cutting edge of the drill bit. Fig. 3 illustrates the relationship between thrust force and feed rate. At the same spindle speed of $1600 \mathrm{rpm}$, the thrust force was averaged decrease $8.53 \%$ in the grapheme oxide suspensions fluid compared with conventional coolant. This is due to increase the feed rate, the shear area is elevated, which leads to cutting force increased [9].

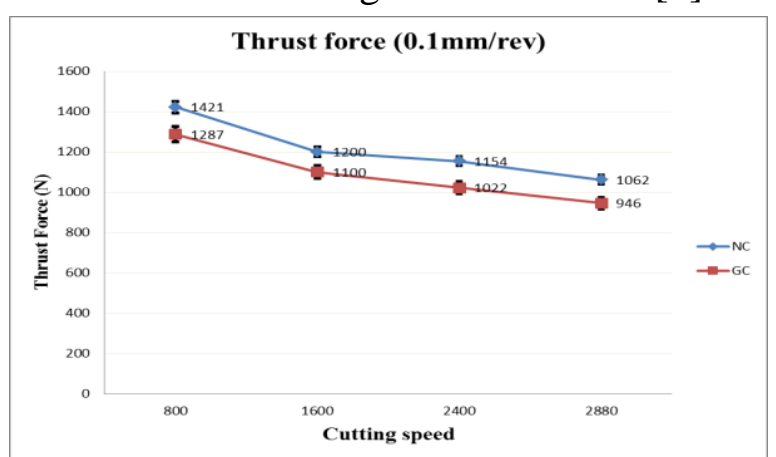

Fig. 2 Thrust force under different cutting speed

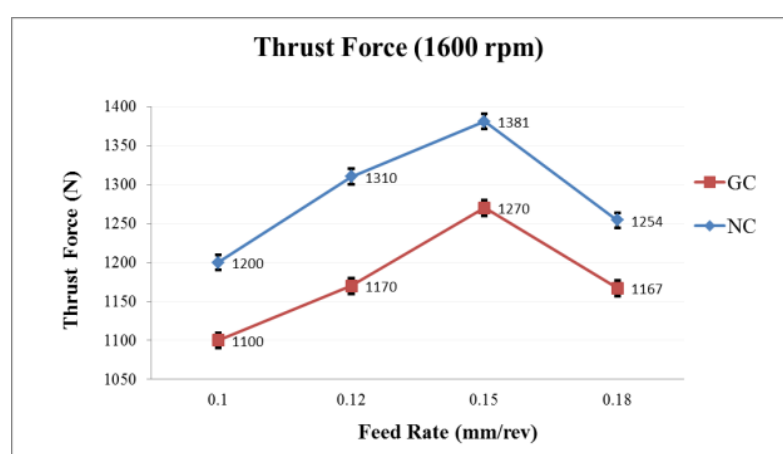

Fig. 3 Thrust force under different feed rate

\subsection{Tool wear}

Flank wear (Fig. 4) is the most severe tool wear occurred in a machining operation [10]. Fig. 5 shows the flank surfaces of the tools used in the drilling experiments. The images were taken by using Alicona microscope and processed with EdgeMasterX. Fig. 5 (a) illustrates the tool used in drilling when graphene oxide suspensions fluid was applied. It can be seen that the wear is much less that shown in Fig. 5 (b), which illustrates the tool used in tests when conventional coolant was applied. In Fig. 5(a) the tool flank wear, $r=17.2 \mu \mathrm{m}$ and in Fig. 5(b) $\mathrm{r}=39.14 \mu \mathrm{m}$. The reduction in flank wear was up to $56.05 \%$. This reduction was due to that graphene oxide suspension fluid has excellent thermal conductivity, which led to a lower cutting temperature and cutting force. The lower cutting force resulted in lower flank wear [11] 


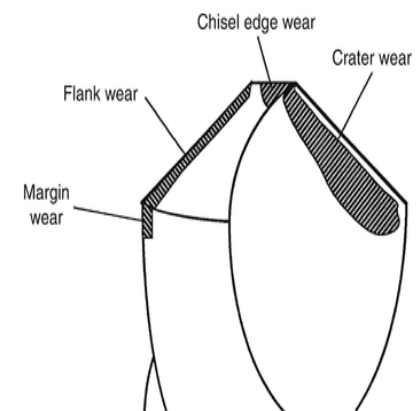

Fig. 4 Main tool wear describe

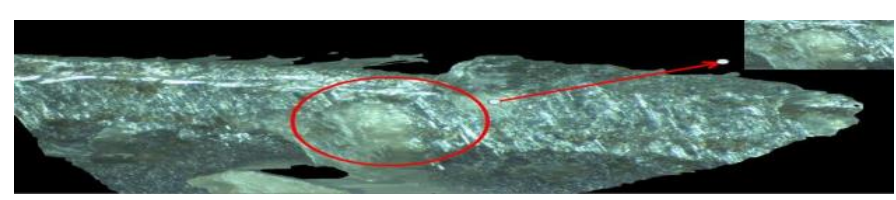

Fig. 5 (a): Tool wear under GO, $r=17.2 \mu \mathrm{m}$

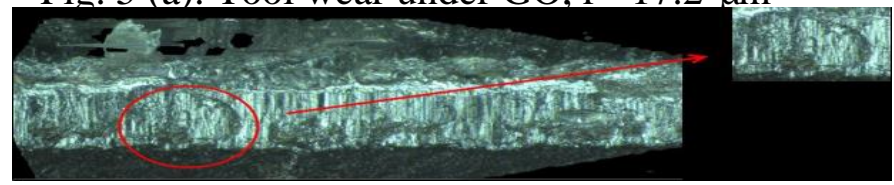

Fig. 5 (b) Tool wear without GO, r= $39.14 \mu \mathrm{m}$

\section{Conclusion}

The effects of conventional cutting fluid and graphene oxide suspensions fluid were investigated in machining Ti-6Al-4V using tungsten carbide tools. Due to the excellent thermal conductivity of graphene oxide suspensions fluid, a significant reduction in cutting force was achieved and less tool flank wear occurred when graphene oxide suspensions fluid was applied in comparison baseline cutting fluid. When spindle speed was $800 \mathrm{rpm}$, the reduction in thrust force reached 9.42\%; when spindle speed was $2880 \mathrm{rpm}$ the thrust force decreased $10.92 \%$. In the meantime, the thrust force is decreased average $8.53 \%$ and tool flank wear declined $56.05 \%$ than conventional coolant when graphene oxide suspensions fluid applied.

\section{References}

[1] Minton, T., et al., Temperature of internally-cooled diamond-coated tools for dry-cutting titanium. International Journal of Machine Tools and Manufacture, 2013. 75: p. 27-35.

[2] Yamaguchi, H., et al., Magnetic Abrasive Finishing of cutting tools for high-speed machining of titanium alloys. CIRP Journal of Manufacturing Science and Technology, 2014: p. 299-304.

[3] Huang, S.T., et al., Drilling of SiCp/Al Metal Matrix Composites with Polycrystalline Diamond (PCD) Tools. Materials and Manufacturing Processes, 2012. 27(10): p. 1090-1094.

[4] Davim, J.P. and F. Mata, Optimisation of surface roughness on turning fibre-reinforced plastics (FRPs) with diamond cutting tools. The International Journal of Advanced Manufacturing Technology, 2004. 26(4): p. 319-323.

[5] Balandin, A.A., et al., Superior thermal conductivity of single-layer graphene. Nano letters, 2008. 8(3): p. 902-907.

[6] Samuel, J., et al., Graphene Colloidal Suspensions as High Performance Semi-Synthetic MetalWorking Fluids. The Journal of Physical Chemistry C, 2011. 115(8): p. 3410-3415.

[7] Chu, B., et al., Graphene-Enhanced Environmentally-Benign Cutting Fluids for HighPerformance Micro-Machining Applications. Journal of Nanoscience and Nanotechnology, 2013. 13(8): p. 5500-5504.

[8] Dreyer, D.R., A.D. Todd, and C.W. Bielawski, Harnessing the chemistry of graphene oxide. Chemical Society Reviews, 2014. 43(15): p. 5288-5301.

[9] Nalbant, M., A. Altın, and H. Gökkaya, The effect of cutting speed and cutting tool geometry on machinability properties of nickel-base Inconel 718 super alloys. Materials \& design, 2007. 28(4): p. 1334-1338.

[10] Wilson, M. and M. Baradie, Cutting Tool Wear and Failure Mechanisms. Environmental Problems in Materials Durability. IDFC 1, 1983: p. 289-303.

[11] Thamizhmanii, S. and S. Hasan. Relationship between flank wear and cutting force on the machining of hard martensitis stainless steel by super hard tools. in Proceedings of the World Congress on Engineering. 2010. World Congress on Engineering 2010. 